To the Editors:

\title{
Impact of new diagnostic criteria for diabetes on its prevalence in a hospital population
}

Ceylon Medical Journal, 2000; 45: 45-46

The criteria for the diagnosis of diabetes mellitus have evolved over several years and until recently were based on the recommendations of the World Health Organization (WHO) of 1985 (1). However, the American Diabetes Association (ADA) in 1997 have advocated that the cutoff value for the diagnosis should be lowered from 7.8 $\mathrm{mmol} / 1$ (WHO value) of venous plasma to $7.0 \mathrm{mmol} / 1$, citing situations where certain individuals with normal blood glucose values according to the WHO criteria would ultimately develop diabetic complications (2). The ADA has also recommended that the oral glucose tolerance test (OGGT) advocated by the WHO should be discontinued, and instead introduced a new category of glucose intolerance called impaired fasting glucose (IFG), when the blood sugar values are in the range of 6.1 to $7 \mathrm{mmol} / 1$. Those with IFG are considered to be an at risk category for future diabetes or cardiovascular disease(3). The WHO, while agreeing that the cutoff value for FBS should be lowered, insists that the OGGT should be continued.

Subsequent to these developments several studies have been conducted in different parts of the world to assess the impact of the altered diagnostic criteria on the prevalence of diabetes. Some of these studies revealed that if the new diagnostic criteria are adopted the prevalence would be less (4), while according to others it would be more (5). The ADA feels that the decrease in identifiable cases of diabetic is justified because the use of FBS 


\section{Letters}

as a means of diagnosis would be more widely used compared to the more cumbersome OGGT and therefore more people will be screened.

I investigated the impact of the altered criteria on the occurrence of diabetes in a hospital population in Sri Lanka. All the FBS values of those who presented to the chemical pathology laboratory of the Teaching Hospital, Peradeniya, with suspected diabetes over a period of 4 months (from 1/ $1 / 1998$ to 30/4/1998) were analysed. Out of a total of 2034 subjects $1212(56 \%)$, were found to be non-diabetic (FBS $<6$ $\mathrm{mmo} / \mathrm{l})$. The table indicates the number of subjects with diabetes and IFG based on the WHO and ADA criteria.

\section{Table. The effect of altered diagnostic criteria on the occurrence of diabetes in a hospital population in Sri Lanka}

$$
\text { WHO (1985) }
$$

$$
\text { ADA (1997) }
$$$$
\text { Diabetes } \quad 533(26 \%)
$$$$
\text { IFG }
$$

The difference between the occurrence of diabetes according to the two sets of criteria is highly significant $(p<0.00047)$. These results do not indicate the true prevalence or incidence of diabetes, as the study was conducted on a selected population. However, it indicates a trend which would reflect a higher prevalence and incidence of diabetes in the community. It is evident that the occur- rence of diabetes would be significantly more if the ADA criteria are adopted, a fact that is of considerable importance for those dealing with this common illness.

\section{Acknowledgements}

I thank Mrs L S Perera, Technician, Department of Medicine for the help rendered during the study.

\section{References}

1. World Health Organization. Diabetes mellitus. Report of a WHO Study Group. Technical Report Series 727. Geneva: WHO; 1985.

2. American Diabetes Association. Report of the Expert Committee on the diagnosis and classification of diabetes mellitus. Diabetes Care 1997; 7: 1183-97.

3. Alberti KGMM. The clinical implications of impaired glucose tolerence. Diabetic Medicine 1996; 13: 927-37.

4. Harris MI, Eastman RC, Cowie CC, Flegal KM, Eberhardt MS. Comparison of diabetes diagnostic categories in the US population according to 1997 American Diabetes Association and 1980-1985 World Health Organization diagnostic criteria. Diabetes Care 1997; 29: 1859-62.

5. DECODE Study Group on behalf of the European Diabetes Epidemiology Study Group. Will new diagnostic criteria for diabetes mellitus change phenotype of patients with diabetes? Reanalysis of European epidemiological data. British Medical Journal 1998; 317: 371-5.

Upali Illangasekera, Associate Professor, Department of Medicine, University of Peradeniya. 